\title{
Relationships between Dendritic Fields and Functional Architecture in Striate Cortex of Normal and Visually Deprived Cats
}

\author{
Albrecht Kossel, ${ }^{1, a}$ Siegrid Löwel, ${ }^{2}$ and Jürgen Bolz ${ }^{1,3}$ \\ 'Friedrich-Miescher Labor der Max-Planck Gesellschaft, 72074 Tübingen, Germany, ${ }^{2}$ Max-Planck Institut für \\ Hirnforschung, 60528 Frankfurt, Germany, and ' INSERM Unité 371 Cerveau et Vision, 69500 Bron, France
}

We examined relationships between the pattern of geniculocortical innervation and the dendritic fields of cells in layer 4 of in cat primary visual cortex. Experiments were performed on normal animals and on cats in which the geniculocortical projection was altered by monocular deprivation or by the induction of divergent squint during the critical period. Thalamic afferents providing the input from the contralateral eye were anterogradely labeled by injecting the fluorescent tracer Dil into lamina $A$ of the lateral geniculate nucleus. Intracellular staining with Lucifer yellow in slice preparations allowed simultaneous visualization of the morphology of individual cells and the thalamic afferents. Our results demonstrate that spiny stellate cells close to the upper and lower margin of the geniculocortical input have highly asymmetric dendritic fields, and thereby confine their dendrites to the termination zone of these afferents. This effect was specific for the cell class; it was not observed in pyramidal neurons. These dendritic asymmetries perpendicular to the laminar borders of spiny stellate cells were not altered by monocular deprivation or strabismus. In contrast, visual deprivation strongly influenced the dendritic arbors of spiny stellate cells near the borders between adjacent ocular dominance columns. In normal animals, the dendrites of cells near columnar borders remained preferentially within one column. These dendritic asymmetries became much more pronounced in strabismic animals. Monocular deprivation weakened the influence of the columnar borders on dendritic fields. Spiny stellate cells within the columns of the open eye exhibited a slight tendency to confine their dendrites to these columns. Cells in the columns of the deprived eye showed the opposite effect; they extended their dendrites preferentially into the adjacent columns of the open eye. These results demonstrate that the segregation of geniculocortical afferents into ocular dominance columns and its perturbation by manipulation of the visual input plays an important role in defining the morphology of cortical target cells. Thus, activity-dependent structural changes not only occur at the level of the presynaptic terminals, but also at the level of

\footnotetext{
Received Sept. 6, 1994; revised Dec. 1, 1994; accepted Dec. 9, 1994.

We thank Iris Kehrer for her help in reconstructing the cells, and Wolf Singer for support.

Correspondence should be addressed to Jürgen Bolz, INSERM Unité 371 Cerveau et Vision, 18 avenue du Doyen Lépine, 69500 Bron, France.

aresent address: Colorado State University, Department of Anatomy and Neurobiology, Fort Collins, CO 80523.

Copyright (C) 1995 Society for Neuroscience $0270-6474 / 95 / 153913-14 \$ 05.00 / 0$
}

the postsynaptic target cells, and thereby contribute to build up the functional architecture of the cortex.

[Key words: visual cortex, ocular dominance columns, cortical layers, plasticity, monocular deprivation, strabismus, dendritic fields, stellate cells, pyramidal cells]

In the visual cortex of adult cats, afferent terminals from the lateral geniculate nucleus (LGN) serving the two eyes are arranged in alternating patches within layer 4 , called ocular dominance columns (Hubel and Wiesel, 1962; Shatz et al., 1977). Transneuronal transport of radioactive amino acids after injections into one eye revealed that in kittens, during the first 2 weeks after birth, the afferents for the two eyes are completely intermixed. Ocular dominance patches then appear to emerge over the next 6 weeks by the progressive segregation of these initially overlapping inputs (LeVay et al., 1978). During this "critical period," alterations in visual experience can cause ocular dominance columns to form abnormally. For instance, if onc cye is closed, the patches of geniculocortical afferents serving the open eye are much wider than the patches serving the closed eye (Wiesel and Hubel, 1965; Shat7, and Stryker, 1978). This change in the anatomical organization of the LGN afferents is paralleled by a physiological shift in the ocular dominance of cortical neurons. In monocularly deprived animals, most cells respond only to the open eye, whereas in normally reared animals, most cells are binocular and respond to stimulation through either eye (Wiesel and Hubel, 1963, 1965). On the other hand, if during the critical period the animals are made strabismic so that the optical axes of the two eyes are no longer aligned and the inputs from the two eyes become uncorrelated, the segregation of the LGN afferents into eye-specific patches is sharper than in normal animals (Shatz et al., 1977; Löwel and Singer, 1992; Löwel, 1994), and most cells respond exclusively to stimulation of either the left or the right eye (Hubel and Wiesel, 1965).

While the formation of ocular dominance columns and its perturbations by alterations in visual experience has been thoroughly studied at the level of geniculocortical afferents, relatively little is known about the consequences of the reorganization of these presynaptic terminals on the morphology of their postsynaptic target cells. Katz et al. (1989) have shown that cells in layer $4 \mathrm{Cb}$ of macaque monkey striate corlex have their dendrites preferentially in that column where the cell body is located, suggesting that the dendritic arbors of individual cells in normal adult animals are related to the columnar organization of the cortex. What is not known, however, is whether changes in visual experience leading to perturbations in the termination pattern of the thalamic afferents also affect the dendritic arbo- 
rization of cells in layer 4 . In other words, do the postsynaptic target cells show a similar degree of structural plasticity as their presynaptic axons?

In the present study, we examined the recipient cells of LGN afferents in the striate cortex of normally reared cats, and in animals with an altered visual experience, that is monocularly deprived and strabismic cats. To this end, we anterogradely labeled geniculocortical afferents representing the contralateral eye by injecting a fluorescent tracer into layer A of the LGN. Subsequent intracellular staining in slice preparations allowed us to visualize simultaneously the morphology of cells in layer 4 and the termination pattern of LGN afferents. Our results indicate that the dendritic fields of spiny stellate cells in layer 4 are shaped by the laminar and columnar border of geniculocortical fibers, and that visual experience during the critical period has a profound influence on the structure of these neurons.

Some of these results have been reported in abstract form (Kossel and Bolz, 1992).

\section{Materials and Methods}

The present study is based on 11 adult cats of both sexes. Four animals were normally reared, four animals had been monocularly deprived (MD) at the age of 3-5 weeks, and three animals were made strabismic (with a divergent squint angle) at the age of 2-3 weeks by sectioning the medial rectus muscle in the left eye. For monocular lid suture and strabismus, anaesthesia was induced with a mixture of ketamine-hydrochloride $(10 \mathrm{mg} / \mathrm{kg})$ and xylazine-hydrochloride $(2.5 \mathrm{mg} / \mathrm{kg})$ injected intramuscularly.

For tracer injections into the lateral geniculate nucleus (LGN), the animals were initially anesthetized with ketamine-hydrochloride (20 $\mathrm{mg} / \mathrm{kg}$, i.m.) with an additional injection of $0.2 \mathrm{ml}$ atropine sulfate (1 $\mathrm{mg} / \mathrm{ml}$ ) and intubated with a tracheal tube coated with local anesthetic (xylocaine). They were then artificially respirated with a mixture of $70 \%$ $\mathrm{N}_{2} \mathrm{O}$ and $30 \% \mathrm{O}_{2}$ and halothane $(0.4-1.0$ vol\%). Respiration was adjusted to a level of $3.5-4.0 \% \mathrm{CO}_{2}$ in the expired air. The cats were placed in a stereotactic framc and paralyzed with pancuronium bromide (initial dose of $0.08 \mathrm{mg} / \mathrm{kg}$, followed by $0.13 \mathrm{mg} / \mathrm{hr}$ ). ECG and the EEG were monitored to control the depth of anesthesia. The body temperature was measured rectally and maintained at $37-38^{\circ} \mathrm{C}$. The pupils were dilated with atropine $(1 \%)$, the nictitating membranes were retracted by Neosynephrine $(1 \%)$, and neutral contact lenses were used to prevent the cornea from drying. The area centralis of both eyes was back projected on a screen in front of the cat by means of a fundus camera.

Using the stereotactic coordinates of the LGN, a trepanation was made above each hemisphere (Horsley-Clark coordinates $4.5-6.5 \mathrm{~mm}$ anterior, 7.5-10 mm lateral). The exact location of the LGN was identified by extracellular recordings with glass electrodes. After the depth of the different layers had been determined, the recording electrode was subsequently replaced by a double barrel electrode that allowed combined recording and dye application. With this clectrode, a sccond penetration was made at the same location as before. By this procedure we could reliably determine the uppermost layer A of the LGN for the injection (Fig. IA). As a tracer we used 5\% Dil (1,1'-dioctadecyl3,3,3',3'-tetramethyl-indocarbocyanine perchlorate, Molecular probes) dissolved in dimethylsulfoxide (DMSO) from which about $0.5 \mathrm{ml}$ were pressure injected into the LGN. The double-barrel electrode was not suitable for the determination of the layers of the geniculate, because the electrode (diameter $100-250 \mu \mathrm{m}$ ) produced a large track throughout all layers within the LGN that subsequently filled up with the injected dye. The leakage of the tracer along the electrode track above the LGN had no effect on the labeling, because DiI was not taken up by fibers of passage. In some experiments we used a second type of electrode that enabled us to inject small DiI crystals into layer A of the geniculate and to record simultaneously the neuronal background activity. In cach hemisphere three to eight injections were made spaced $0.5-1.0 \mathrm{~mm}$ apart.

Intracellular injections of Lucifer yellow in fixed slices. After a survival time of 2-4 weeks, the animals were deeply anesthetized with ketamine-hydrochloride $(200 \mathrm{mg} / \mathrm{kg}$, i.m.) in combination with chloralhydrate $(8 \mathrm{ml}, 7 \%$, i.p.). The animals were perfused transcardially with a preflush containing $50 \mathrm{gm} /$ liter sucrose, $5 \mathrm{mg} / \mathrm{ml}$ lidocaine, $0.28 \mathrm{mg}$ heparin in $0.05 \mathrm{M}$ phosphate buffer $(\mathrm{PB}) \mathrm{pH} 7.4$, followed by $4 \%$ paraformaldehyde in PB for about $20 \mathrm{~min}$. The brains were then removed and postfixed for $0.5 \mathrm{hr}$ or transferred directly into cold PB. The LGN of each hemisphere was cut on a vibratome ( $300 \mu \mathrm{m}$ thickness) to determine the size and the location of the injection sites (Fig. 1A). Blocks of cortical tissue containing the region of area 17 were cut into $250-300 \mu \mathrm{m}$ slices and examined under the fluorescent microscope to select those slices that contained anterogradely labeled afferents in layer 4. These slices were then transferred into cold PB and stored for subsequent intracellular injections.

For intracellular injection, the slices were transferred to a chamber installed at the stage of an epifluorescent microscope (Zeiss, ACM) equipped with a long distance objective $(\times 20$, Leitz). The fluorescent labeling of the afferents from the LGN allowed to identify the location of layer 4 and to place the injection electrode at the proper region into the tissue. The electrode was advanced in steps of 3-5 $\mu \mathrm{m}$ through the tissue by means of an electromechanical stepper. Penetration of the cells was done under visual control. The cells were injected intracellularly with Lucifer yellow $(8-10 \%$ in $0.1 \mathrm{mM} \mathrm{LiCl})$ by applying negative current pulses $(2-4 \mathrm{nA}, 4 \mathrm{~Hz}, 200 \mathrm{msec}$ on, $50 \mathrm{msec}$ off) for $2-5 \mathrm{~min}$. Sections with successfully filled neurons (see Fig. $1 D$ ) were transferred into cold fixative and postfixed for 3-14 d.

Reconstruction and analysis of anterograde labeling and the cell morphology. The analysis of the anterograde labeling was performed in the thick slices, since cutting the slices with the freezing microtome reduced the DiI labeling. With the appropriate filter sets for Lucifer yellow and DiI, it was possible to determine the pattern of the anterograde labeling as well as the position of the cell body and the primary dendrites. Using an epifluorescent microscope equipped with a camera lucida, drawings were made from the anterograde labeling in layer 4 and from the cells and their position relative to the borders of the afferents. Determining the exact location of the borders of ocular dominance columns in $300 \mu \mathrm{m}$ thick slices could potentially lead to an overestimation of the labeled columns versus the unlabeled columns, if the borders do not run parallel to the z-plane of the slice. Therefore, for each experimental condition, we injected and analyzed about the same number of cells in the labeled versus unlabeled columns (normal animals, $65 \%$ vs $35 \%$; MD animals, deprived cyc columns, $59 \%$ vs $41 \%$; MD animals, nondeprived columns, $55 \%$ vs $45 \%$; strabismic animals, $46 \%$ vs $54 \%$ ). In addition, the analysis of dendritic asymmetries near columnar borders described in the result section ("bias-index") does not depend upon the exact location of the columnar border, it only requires the information whether the border is to the left or to the right of the cell body.

For analysis and reconstruction of the detailed morphology of the cells, the slices were immersed in $30 \%$ sucrose and cut further on a freezing microtome at a thickness of $60 \mu \mathrm{m}$. The sections were mounted on subbed slides, dehydrated, cleared, and coverslipped with entellan (Merck). The cells were then drawn with a $\times 40$ oil objective. In these thin sections the anterograde labeling was destroyed, since the lipophilic DiI was washed out by the dehydration procedure. The reconstruction of the detailed morphology of the cells was therefore done without knowledge of the location of the laminar and columnar borders. The drawings of the detailed morphology of the cells were then aligned and combined with the drawings of the crude morphology of the cells and their location at the afferent borders.

For quantitative measurements of the dendritic fields of the cells, a Sholl analysis was carried out (Sholl, 1953). To this end, concentric circles with a spacing of $25 \mu \mathrm{m}$ were drawn around the cell body and the number of intersections of all dendritic branches with the circles was counted. To measure the soma sizes, camera lucida drawings of the injected cell somata (using a $\times 100$ immersions objective) were entered with a digitizing tablet into a computer that calculated the soma areas. The spine density was determined on $50-100 \mu \mathrm{m}$ long dendritic segments beginning at a distance of $30 \mu \mathrm{m}$ from the soma by using a $\times 100$ immersion objective and an ocular grid.

\section{Results}

DiI injections into the LGN resulted in an intense anterograde labeling of geniculocortical afferents in layer 4 . It also produced a bright retrograde labeling of the somata of corticothalamic cells in layer 6 that often masked a faint anterograde labeling in this layer (Fig. 1). All injections that were located in lamina A of the LGN revealed distinctly labeled ocular dominance col- 

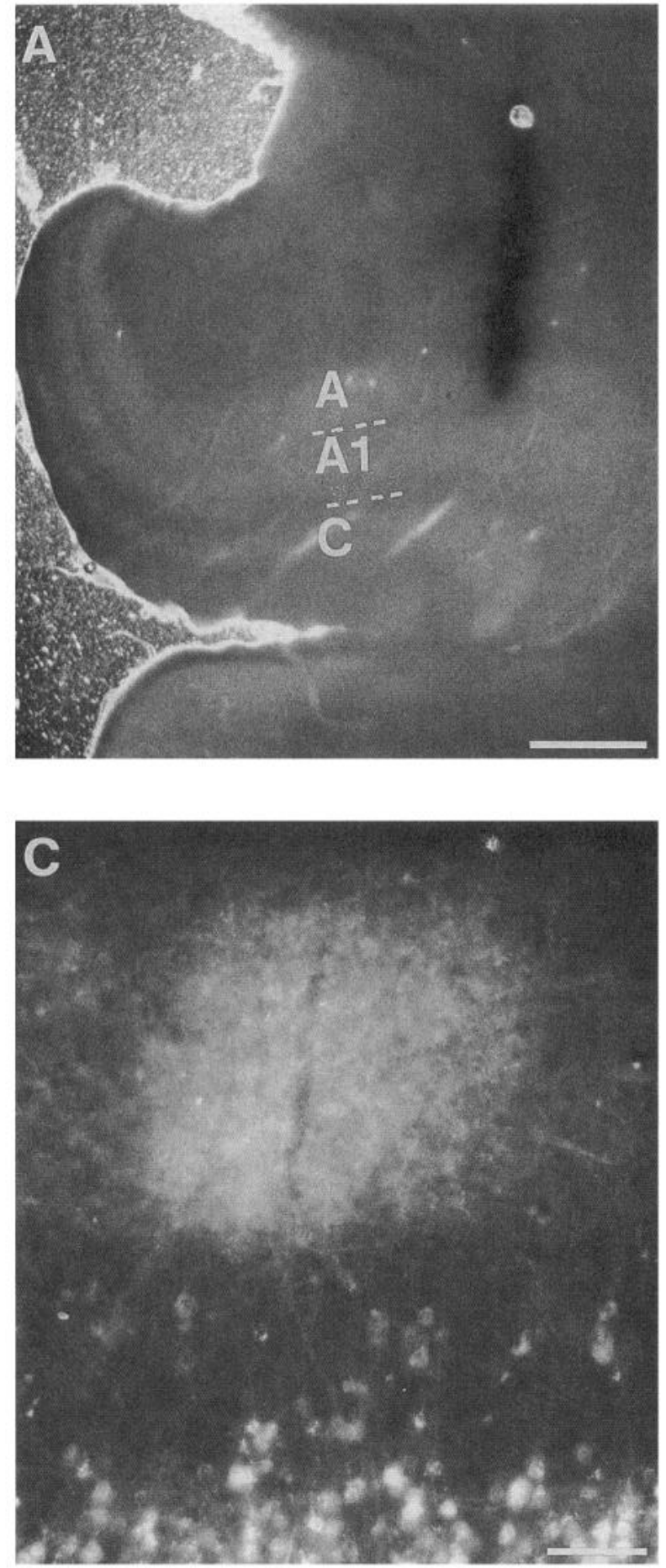
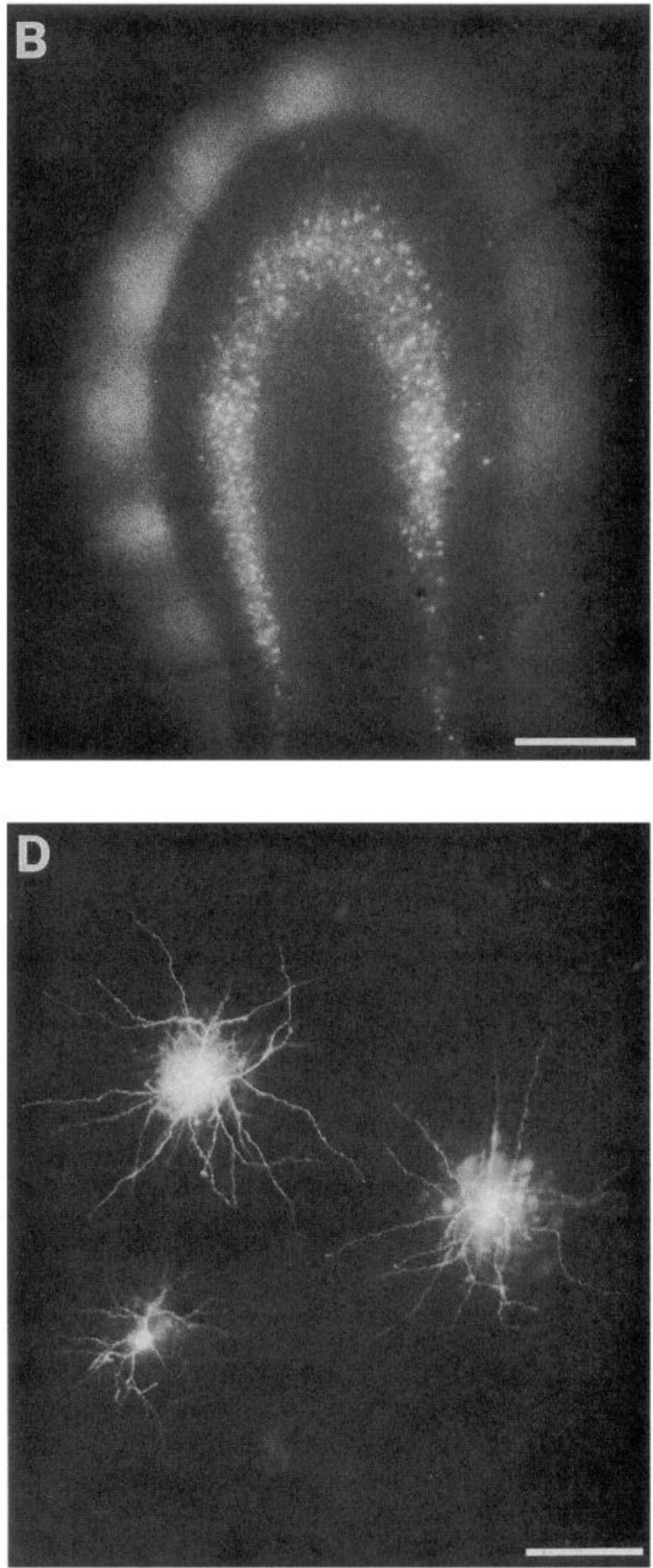

Figure 1. A, Photomicrograph of a sagittal section through the lateral geniculate body (LGN) of a normally raised cat with a DiI injection in layer A. The dye was injected by pressure through a micropipette after the geniculate layers (indicated in the micrograph) were determined via electrophysiological recordings. B. Pattern labeling in a frontal section through area 17 of the same animal after several closely spaced DiI injections. Anterogradely transported DiI revealed the ocular dominance columns within cortical layer 4 . In addition, there are brightly fluorescent retrogradely labeled somata of the corticothalamic projection neurons in layer 6. $C$, Anterogradely labeled single ocular dominance column at higher magnification. $D$, Micrograph of spiny stellate cells filled intracellularly with Lucifer yellow. Scale bars: $A$ and $B, 1 \mathrm{~mm} ; C$ and $D, 100 \mu \mathrm{m}$.

umns in cortical layer 4 . Figure $1 B$ shows an example where several closely spaced injections in the LGN covered a large area of the visual field and thereby labeled many ocular dominance columns within the corresponding part of area 17. Since we were particularly interested in relationships between the cells' dendritic morphology and the pattern of geniculate affer- ents, we attempted to fill cells preferentially near the laminar and columnar borders of the thalamic input. From all intracellularly stained neurons, only those were selected for further analysis which (1) showed a complete fill of their dendrites and (2) where the position of the cell with respect to the afferent borders could be determined. 
Table 1. Morphometric analysis of cells within layer 4 of normal and visually deprived cats

\begin{tabular}{|c|c|c|c|c|}
\hline & Soma area & $\begin{array}{l}\text { Number of } \\
\text { basal dendrites }\end{array}$ & $\begin{array}{l}\text { Radius of basal } \\
\text { dendritic field }\end{array}$ & $\begin{array}{l}\text { Spine } \\
\text { density } \\
\text { (spines/ } \\
10 \mu \mathrm{m} \text { ) }\end{array}$ \\
\hline \multicolumn{5}{|l|}{ Normal } \\
\hline Stellate cells & $141 \pm 34 \mu \mathrm{m}^{2}$ & $6 \pm 1(4-9)$ & $147 \pm 20 \mu \mathrm{m}$ & $2.5+/ 4.0$ \\
\hline Pyramidal cells & $144 \pm 33 \mu \mathrm{m}^{2}$ & $4 \pm 1(2-6)$ & $141 \pm 19 \mu \mathrm{m}$ & ND \\
\hline \multicolumn{5}{|l|}{ MD/open } \\
\hline Stellate cells & $142 \pm 43 \mu m^{2}$ & $6 \pm 1(3-8)$ & $148 \pm 16 \mu \mathrm{m}$ & $2.9+/ 4.0$ \\
\hline Pyramidal cells & $125 \pm 19 \mu \mathrm{m}^{2}$ & $4 \pm 2(3-8)$ & $152 \pm 22 \mu \mathrm{m}$ & ND \\
\hline \multicolumn{5}{|l|}{ MD/closed } \\
\hline Stellate cells & $138 \pm 26 \mu \mathrm{m}^{2}$ & $6 \pm 1(3-8)$ & $148 \pm 23 \mu \mathrm{m}$ & $3.05+/ 4.0$ \\
\hline Pyramidal cells & $133 \pm 33 \mu \mathrm{m}^{2}$ & $4 \pm 1(3-8)$ & $138 \pm 13 \mu \mathrm{m}$ & ND \\
\hline \multicolumn{5}{|l|}{ Strabismic } \\
\hline Stellate cells & $144 \pm 44 \mu m^{2}$ & $6 \pm 1(4-9)$ & $141 \pm 24 \mu \mathrm{m}$ & $3.0+/ 2.0$ \\
\hline Pyramidal cells & $143 \pm 20 \mu \mathrm{m}^{2}$ & $5 \pm 1(3-7)$ & $142 \pm 22 \mu \mathrm{m}$ & ND \\
\hline
\end{tabular}

A total of 304 cells from cortical layer 4 were drawn: 114 cells were obtained from animals with normal visual experience, 130 cells from monocularly deprived cats, and 60 cells from strabismic animals. In a first set of experiments, cells were filled without preference for a certain type of cell. Out of this sample $(n=114), 54 \%$ of the cells were identified as spiny stellate cells, $25 \%$ had the characteristic morphology of pyramidal cells, and only $8 \%$ of the neurons were spine-free cells with multipolar or bipolar morphology. The morphology of the remaining cells (12\%) was intermediate between spiny stellate cells and pyramidal cells, they possessed an ascending dendrite that was only slightly longer than the rest of their dendrites. Most of these

\section{Sholl analysis}

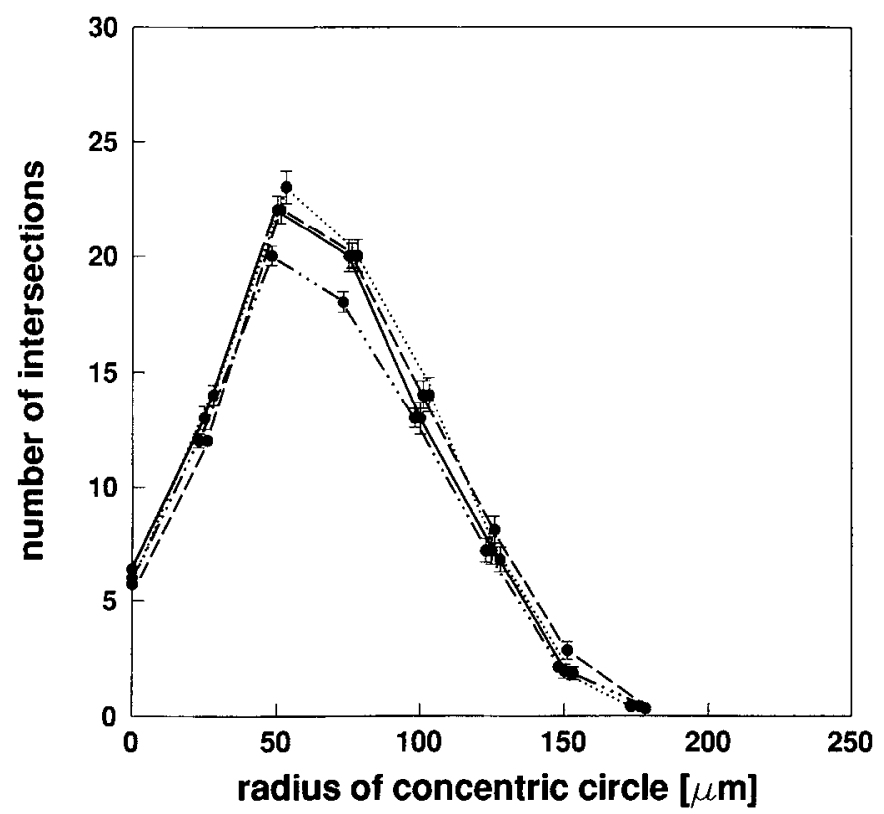

Figure 2. Sholl analysis of spiny stellate cells within layer 4 of cat area 17. There was no significant difference between cells from normal, strabismic, and monocularly deprived animals. Symbols: normal (solid line), squinting (dash-dot line), monocularly deprived open eye (dashed line), monocularly deprived closed eye (dotted line). cells were found near the lower boundary of layer 4 . These observations either indicate that there exists a continuum of form between spiny stellate and pyramidal cells in layer 4 , or that these cells represent a separate class of neurons that Lorente de Nó (1938) called "star pyramids." Since we recovered only a relatively small number of "star pyramids" and spine-free cells, these neurons were not further analyzed.

For both spiny stellate and pyramidal cells in cortical layer 4 , we measured soma size, spine density, number of primary dendrites, and radius of the dendritic fields. The only significant difference between the two groups of neurons was found in the number of dendrites: spiny stellate cells possessed four to nine and pyramidal cells only two to six primary dendrites (Table 1). Monocular deprivation and artificially induced strabismus had no effect on any of these morphological parameters. In monocularly deprived animals, Lucifer yellow-injected cells were either located in the columns of the open eye or in the columns of the closed eye. When analyzed separately, cells in either column did neither differ significantly in the above-mentioned morphological features from each other nor from cells in normal animals. Moreover, a Sholl analysis also revealed no differences between cells in normal and deprived ocular dominance columns (Fig. 2).

In the following sections, the relationships between the dendritic trees of layer 4 cells and the termination pattern of the geniculocortical afferents are examined. To this end, the shape of dendritic fields near the laminar and columnar borders of the geniculate afferents were analyzed. In each case, we will first describe cells in normal animals and then cells in animals with altered visual experience (monocular deprivation and divergent strabismus).

\section{Dendritic fields at laminar borders of thalamic afferents: normal animals}

Geniculocortical afferents in area 17 , as visualized by anterograde DiI labeling, terminate in layer 6 and in a $300-450 \mu \mathrm{m}$ wide band about in the middle of the cortical thickness. The lower border of this band was extremely sharp; it coincided with the boundary between layers 4 and 5. The upper border was less sharply delineated and extended into the deep part of layer 3, as previously described (Rosenquist et al., 1974; LeVay and Gilbert, 1976). An example of a cell close to the lower border of 

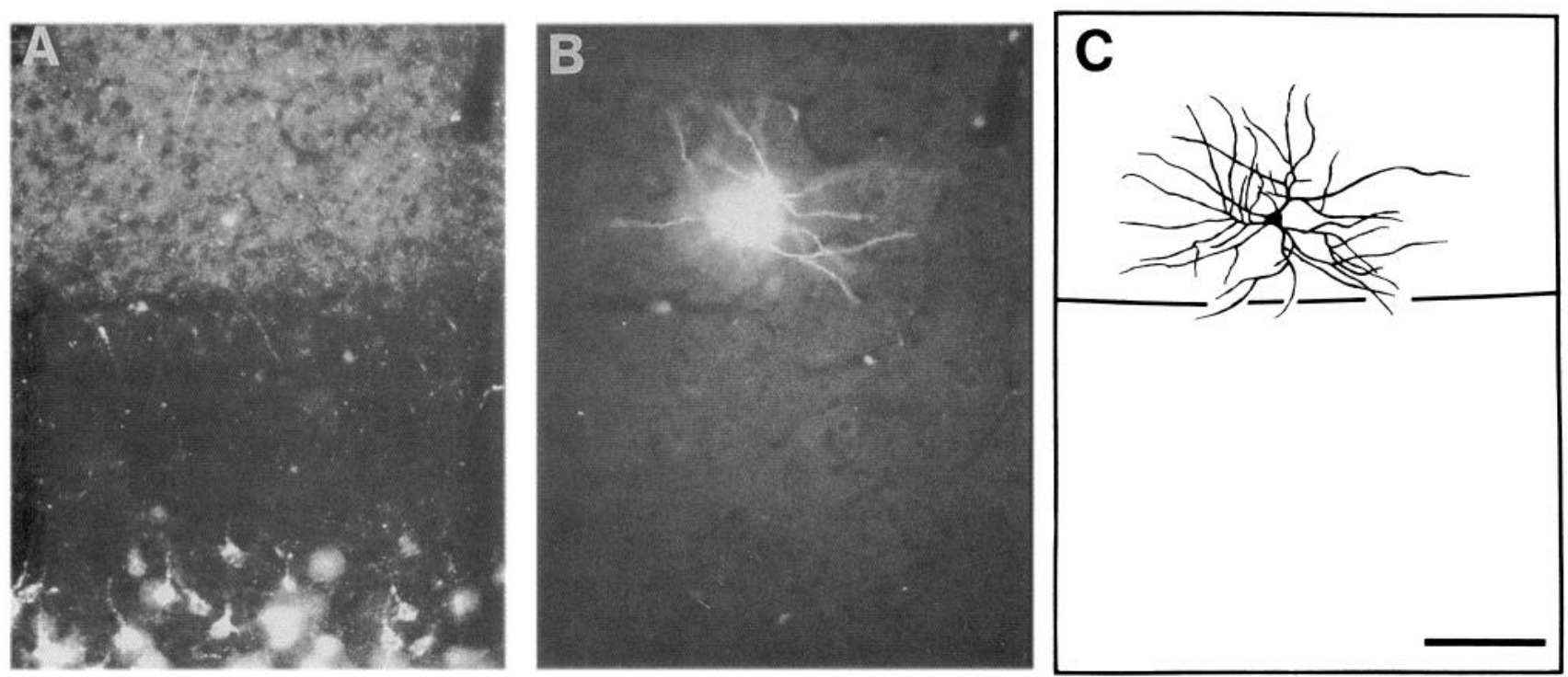

Figure 3. Dendritic fields at laminar borders. Reconstruction of cell morphology and the pattern of thalamic afferents in a normally raised cat. Fluorescence photomicrograph of $(A)$ DiI-labeled afferents in a $300 \mu \mathrm{m}$ slice and $(B)$ of a Lucifer yellow-filled spiny stellate cell in a $60 \mu \mathrm{m}$ section from the same slice. $C$, Combined drawing of the dendritic morphology of the cell and the lower border of the thalamic afferents. The drawing of the cell was reconstructed from several sections, whereas only the section containing the cell body is shown in $B$. Scale bar, $100 \mu m$.

the thalamic afferents is illustrated in Figure 3, which shows the DiI labeled thalamic afferents (Fig. $3 A$ ), a spiny stellate cell filled with Lucifer yellow (Fig. $3 B$ ) and the reconstruction of the afferent border with the detailed dendritic morphology of the injected cell (Fig. 3C). The cell's dendritic field had a marked asymmetry; most dendrites were directed away from the border. Some dendrites first run straight toward the border (proximal dendrites) and then redirect their course and bend away from the border (distal dendrites).

A representative sample of spiny stellate cells in layer 4 is illustrated in Figure 4. All cells in the middle of layer 4 had symmetrical dendritic fields relative to the laminar borders. In contrast, cells near the boundary between layer 4 and 5 , that is, at the lower border of the thalamic afferents, had strongly asym-

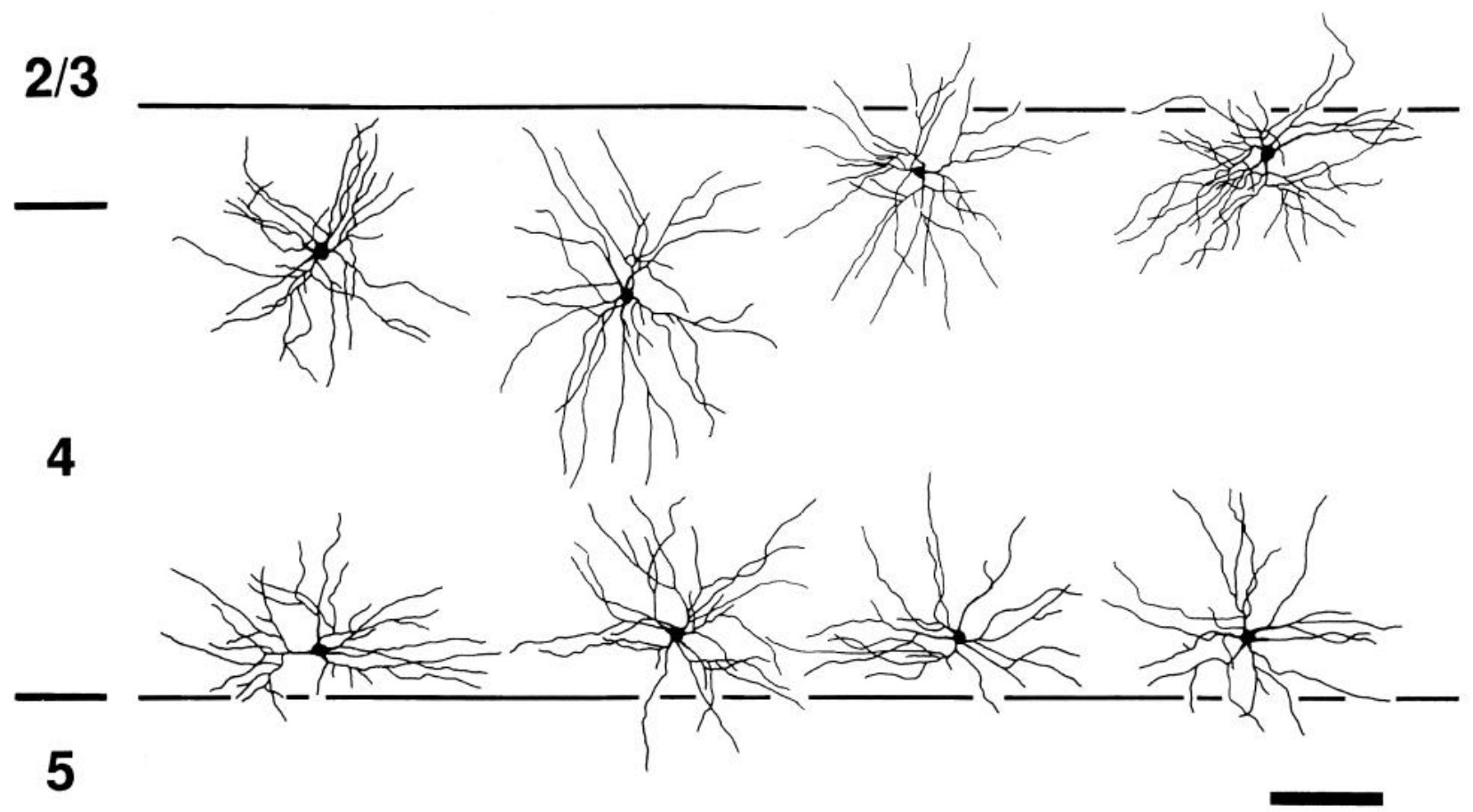

Figure 4. Dendritic morphology of spiny stellate cells in area 17 of normal cats. Cells in the middle of layer 4 have nearly symmetrical dendritic fields. Cells in the vicinity of the upper and the lower border of the thalamic afferents, however, have asymmetric dendritic fields; their dendrites are confined of the afferent projection zone. Note that the lower border of thalamic afferents corresponds to the layer $4 / 5$ border, whereas the upper borders extends into the deep part of layer 3 (and therefore does not correspond to a laminar border). Scale bar, $100 \mu \mathrm{m}$. 
A

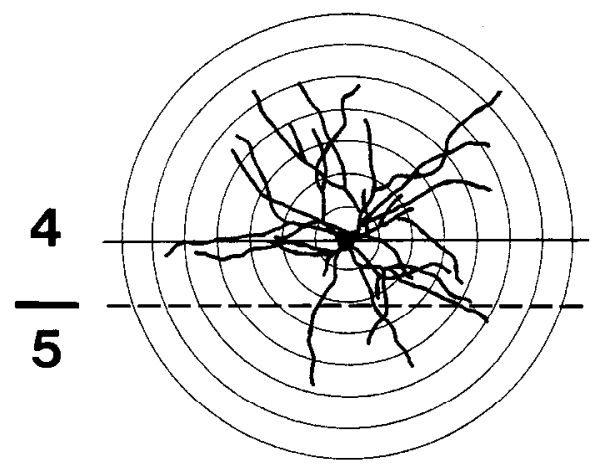

B

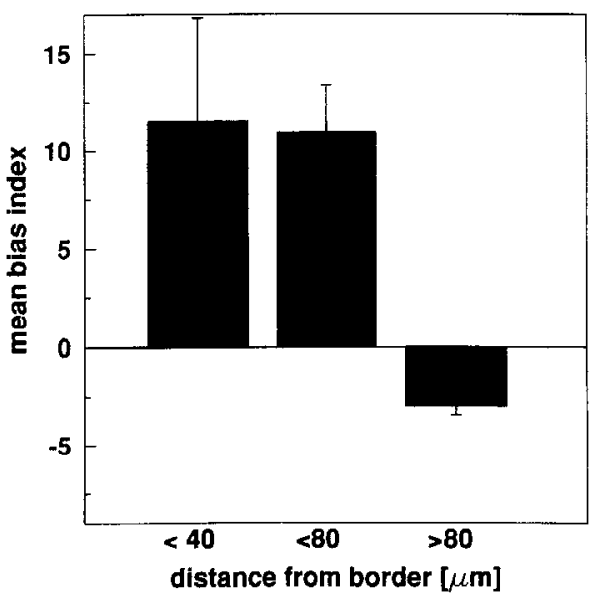

Figure 5. Quantitative analysis of the dendritic asymmetry of spiny stellate cells in normal animals as a function of the distance from the lower laminar border of the thalamic afferents, the layer $4 / 5$ border. $A$, The dendritic fields were bisected by a line (solid line) running through the cell body and parallel to the laminar border (dashed line), and the number of intersections of all dendrites with the concentric circles was counted separately for each half-field. The bias of the cells was then determined by subtracting the number of intersections in the half-field facing away from the border from the number of intersections facing toward the border. $B$, Cells in the vicinity of the border (within $80 \mu \mathrm{m}$ ) possess a positive mean bias index (left two columns), indicating that their dendritic fields are biased away from the border. Spiny stellate cells further away from the border (distance $>80 \mu \mathrm{m}$ ) were nearly symmetrical. Error bars are SEM; numbers of cells (at each distance) are 6,19 , and 44 .

metric dendritic fields such that most of their dendrites were confined to the thalamic recipient zone. In order to quantify this asymmetry, we bisected the dendritic fields of all cells $(n=69)$ by a line running through the cell body and parallel to the laminar border of the thalamic afferents. In each half-field, the number of intersections between the dendrites and the concentric Sholl circles (distance $25 \mu \mathrm{m}$ ) was counted (Fig. $5 A$ ). This allowed us to determine the bias of the cells' dendritic fields. The bias was calculated by subtracting the number of dendritic intersections facing away from the border from the number of dendritic intersections facing toward the border. A positive bias-index indicates that the cell has more dendrites on the site oriented away from the border; a bias-index near 0 indicates that the dendritic field was symmetrical. As illustrated in Figure $5 B$, spiny stellate cells in the vicinity of the border between layer 4 and layer 5 (cell body distance $<80 \mu \mathrm{m}$ ) show a very pronounced bias. The positive bias indices up to a distance of $80 \mu \mathrm{m}$ demonstrate that the dendritic fields are strongly asymmetrical. The numbers of intersections toward and away from the border significantly differed from each other ( $p<0.05$; Wilcoxon rank test). At distances more than $80 \mu \mathrm{m}$ away from the border, which corresponds to approximately half of the dendritic radius, the cells are nearly symmetrical, with slightly more dendrites in the lower part of their dendritic field (Fig. $5 B$, right column).

As mentioned above, the lower border of the geniculate afferent zone coincides with the laminar border between layers 4 and 5. The upper border of the geniculate afferents, however, does not correspond to an interlaminar border. It extends beyond layer 4 and reaches the bottom part of layer 3 . As illustrated in Figure 4, the dendrites of spiny stellate cells at the top of layer 4 freely crossed the border between layers 4 and 3. For almost all of these cells, the upper border of the thalamic afferents was beyond the reach of their dendrites. Only cells located in deep layer 3 were close enough to reach this border with their dendrites. Since most cells in layer 3 are pyramidal cells, we recovered only five spiny stellate cells situated near the upper border of the geniculocortical afferents. Figure 4 shows two representative examples of such cells. Similar to the situation at the lower border, spiny stellate cells had asymmetric dendritic arbors and thereby confined most of their dendrites to the recipient zone of the thalamic afferents.

Unlike spiny stellate cells, analysis of the morphology of pyramidal neurons near the borders of thalamic afferents revealed that their basal dendrites were not affected by the presence of the border. As illustrated in Figure 6, pyramidal cell dendrites frecly crossed both the upper and the lower border of the termination zone of the geniculate afferents. Thus, the influence of the thalamic afferents on the shape of dendritic fields is cell specific: only spiny stellate cells, but not pyramidal cells, are affected by abrupt changes of afferent input.

\section{Dendritic fields at laminar borders of thalamic afferents: monocularly deprived and strabismic animals}

A major goal of this study was to examine whether disruption of the normal balance of visual stimulation by monocular deprivation in early life affects the structure of cortical cells in the thalamic recipient zone. Since we visualized the ocular dominance columns by anterograde DiI labeling, it was possible to compare the dendritic morphology of cells in the columns of the occluded eye with cells in the columns of the eye that had remained open. Examples of spiny stellate cells filled with Lucifer ycllow in monocularly deprived animals are shown in Figure 7. Similar to the observations made in normal animals, the cells were strongly biased away from the border; most dendrites of these cells avoided to cross the lower border of the thalamic afferents (corresponding to the layer $4 / 5$ border), irrespective of whether the cells were located in the columns of the open eye ( $n=28$ ) or of the closed eye $(n=26)$. This dendritic asymmetry of spiny stellate cells near the layer $4 / 5$ border was also observed in strabismic animals.

A total of six spiny stellate cells in the upper part of layer 4 was stained in monocularly deprived animals. As in normal animals, their dendrites freely crossed the interlaminar border between layers 4 and 3. None of these cells, however, was very close to the upper border of the geniculate afferents; therefore, we do not know whether the dendrites of spiny stellate cells in monocularly deprived animals respect this border or not. Anal- 


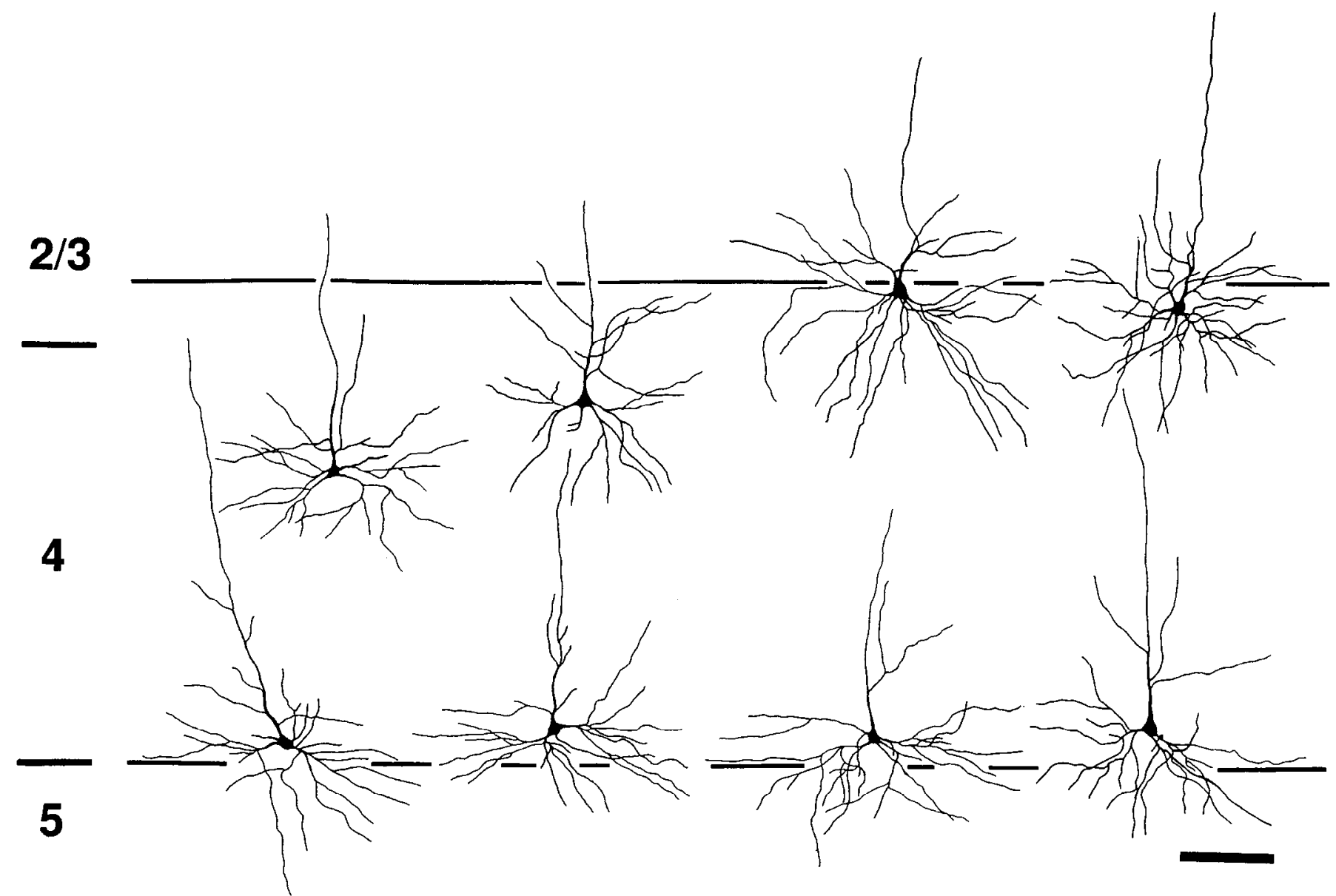

Figure 6. Dendritic morphology of pyramidal cells in normal cats. The dendritic fields of pyramidal cells were not affected by the thalamic afferents, since most of their dendrites freely cross the borders of the termination zone of the thalamic afferents (indicated by the solid lines). Scale bar, $100 \mu \mathrm{m}$.

ysis of pyramidal cells in layer 4 and lower layer 3 in both monocularly deprived and strabismic cats indicated that the basal dendrites of these cells were not influenced by the upper or lower border of the geniculate afferents-as in normal animals.

\section{Dendritic fields at columnar borders: normal animals}

An individual ocular dominance column anterogradely labeled by $\mathrm{DiI}$ is shown in Figure $1 C$, and examples of spiny stellate cells reconstructed close to columnar borders are illustrated in Figure 8 . The cells appear to have fewer dendrites running toward the border than running away from it. Frequently, the dendrites oriented toward the border were shorter than those oriented parallel to or away from the border. The bias of the dendritic fields of the total sample of cells (Fig. 9, $n=51$ ) was analyzed quantitatively. Cells further away than $80 \mu \mathrm{m}$ from the border, which is approximately half of the dendritic radius, had nearly symmetrical dendritic fields. However, $82 \%(n=11)$ of the spiny stellate cells close to the border (cell body distance $<$ $40 \mu \mathrm{m}$ ) had a positive bias index, indicating that dendritic fields were biased away from the border. The number of dendritic intersections in each half-field of these cells significantly differed from each other $(p<0.05$; Wilcoxon rank test). In comparison with dendritic asymmetries observed near the horizontal borders of thalamic afferents (Figs. 3,4), the asymmetries near the columnar borders were less pronounced. Usually, spiny stellate cells had always some dendrites that crossed the columnar borders. Therefore, we used an additional test to analyze the cells' dendritic field near the borders of ocular dominance columns.

To this end we determined the number of intersections between the Sholl circles and the dendrites that actually crossed the columnar borders. The cells were then mirror imaged at a line running through the cell body and parallel to the columnar border, and the number of intersections beyond the border was again counted and compared with the original value (see Fig. 10). The difference between the two values was used to calculated a "mirror index" (Hübener and Bolz, 1992). If there are more dendritic intersections beyond the border in the mirrored position than in the original position (mirror index $>0$ ), the cells' dendrites avoided crossing the border. This was true for the majority of the cells from our sample. Near the columnar border (cell body distance $<80 \mu \mathrm{m}$ ), the majority of the cells $(64 \%, n=31)$ had a positive mirror index and the number of intersections in the neighboring column significantly differed from the number of intersections in the mirrored position $(p<$ 0.05; Wilcoxon rank test; Fig. 10). The same test applied to spiny stellate cells located within the same distance near the lower border of thalamic afferents, the layer $4 / 5$ border, revealed that $94 \%(n=25)$ of the cells had a positive mirror index and that the magnitude of the effect was more pronounced than at the columnar border $(p<0.005$; Wilcoxon rank test; compare 
2/3

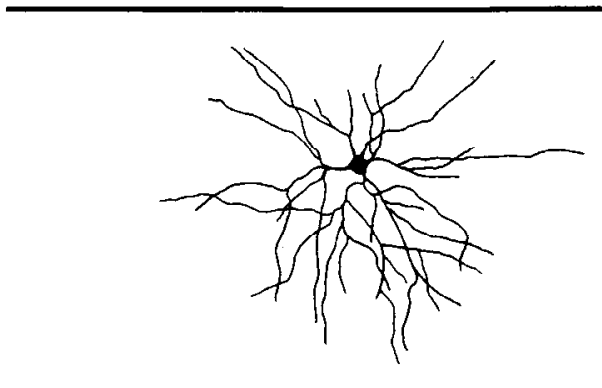

4
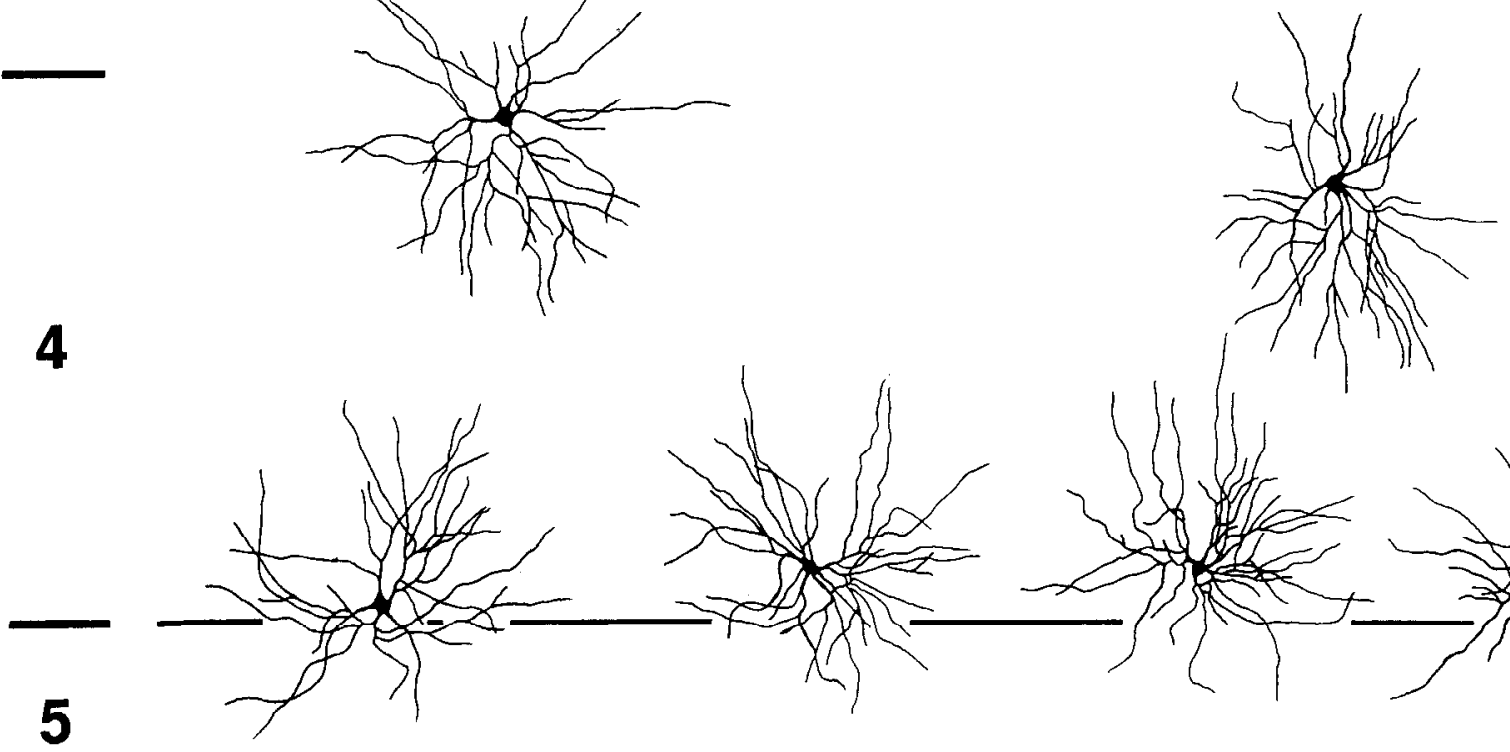

Figure 7. Dendritic fields at laminar borders. Spiny stellate cells in layer 4 of monocularly deprived $(M D)$ cats. Like in normal animals, the dendrites tend to stay within the termination zone of the thalamic afferents, independent of whether the cells are located in the columns of the open or the deprived eye. Scale bar, $100 \mu \mathrm{m}$.

\section{normal}
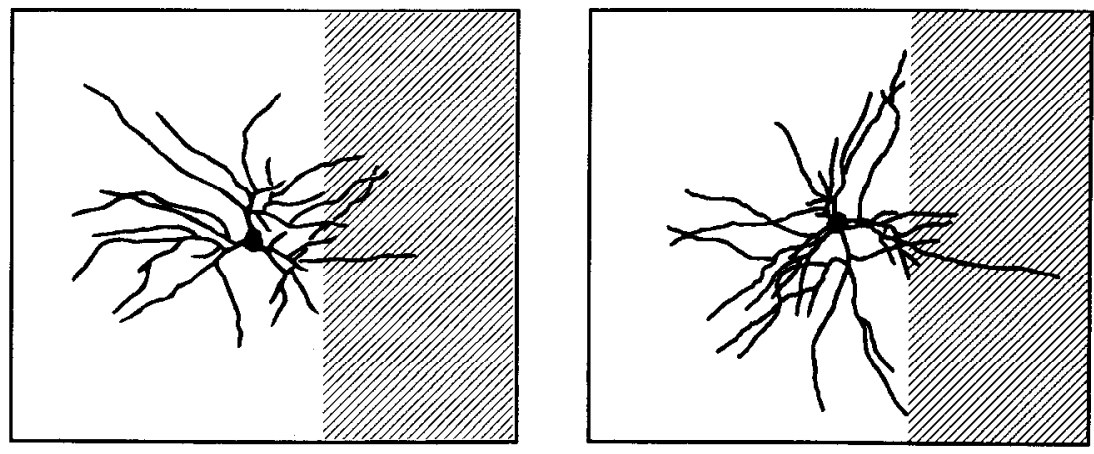

\section{strabismic}

Figure 8. Dendritic fields at columnar borders. Reconstruction of the morphology of spiny stellate cells near the borders between ocular dominance columns (hatched regions) in (a) normal and $(b)$ in strabismic animals. The cells have asymmetric dendritic fields and fewer dendrites are oriented toward the border than oriented away from the border. Scale bar, $100 \mu \mathrm{m}$.
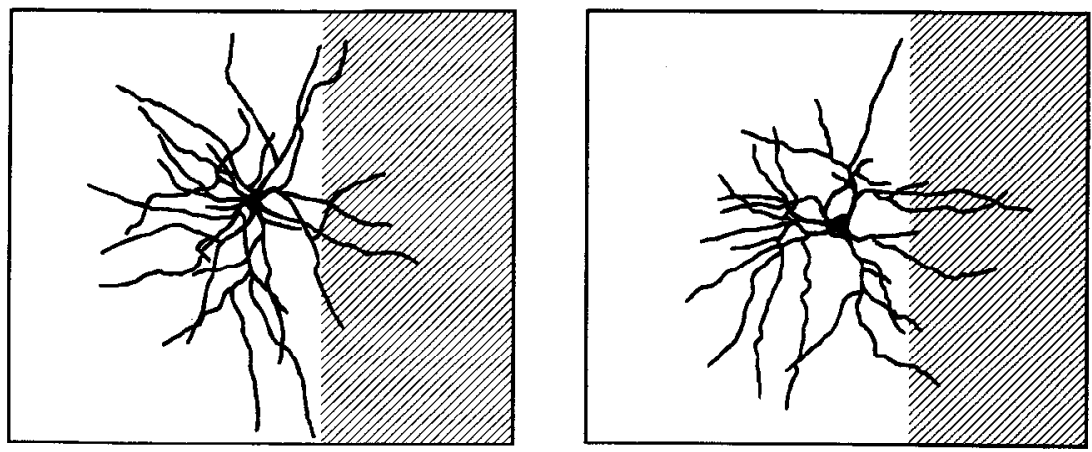
A

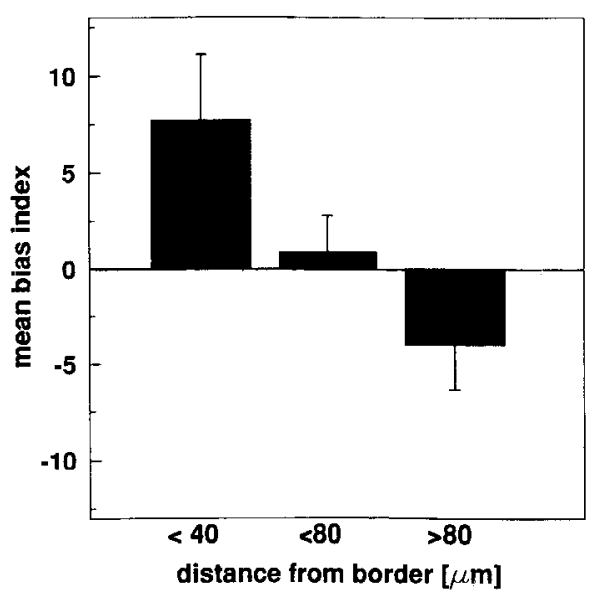

C

MD/open column

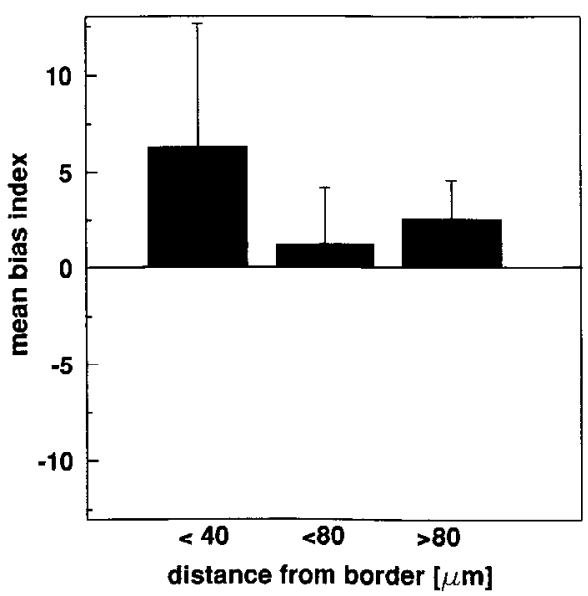

B

\section{strabismic}
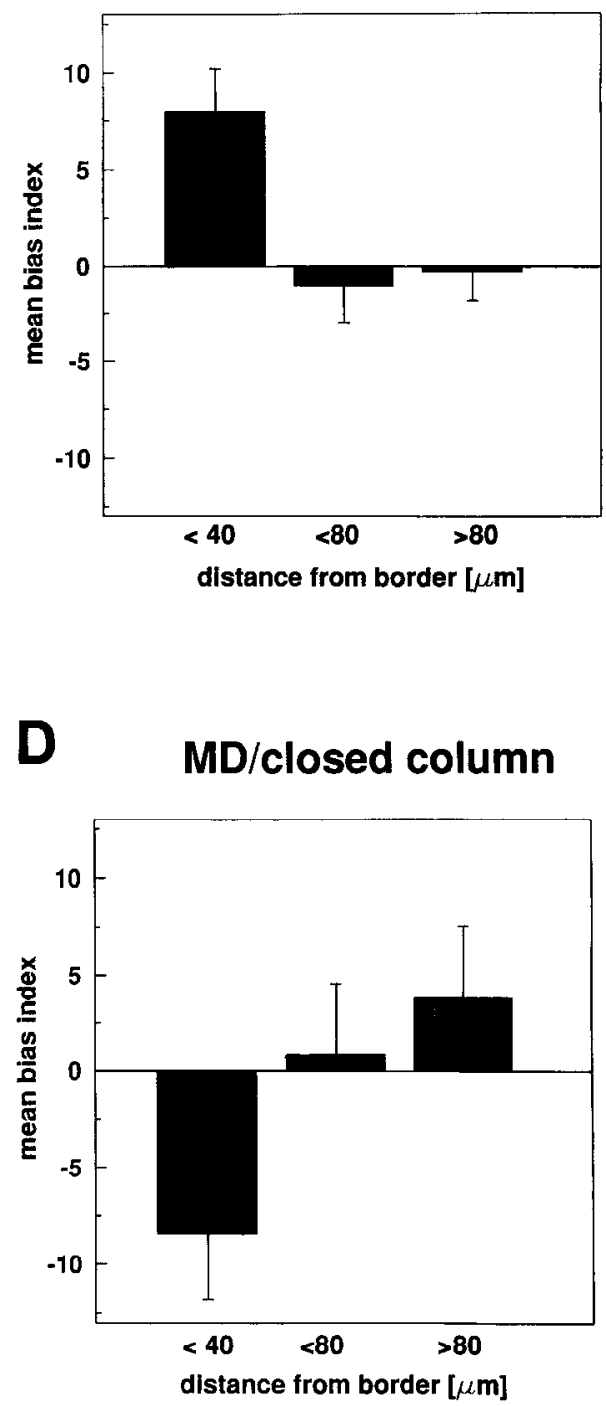

Figure 9. Bias index of spiny stellate cells at various distances from ocular dominance borders. Within $40 \mu \mathrm{m}$ from the border, cells in (a) normal animals, $(b)$ strabismic animals, and (c) cells in the columns of the open eye in monocularly deprived animals $(M D /$ open column) have a positive bias index. Thus, the dendrites of these cells are biased away from the columnar borders. $D$, In contrast, cells in the columns of the deprived eye in monocu-

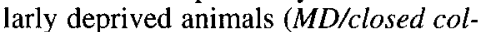
umn) have, on the average, a negative bias index, indicating that their dendrites are biased toward the columns of the open eye. Error bars are SEM; numbers of cells (at each distance) are $11,20,20$ (normal animals) 14, 13, 30 (strabismic animals) 3, 16, 26 (MD animals, open columns) and $7,14,16$ (MD animals, closed columns).
4/5 and normal columns in Fig. 10). This quantitative analysis confirmed the qualitative impression that laminar borders had a stronger effect on the shape of the dendritic fields of spiny stellate cells than columnar borders.

Cells laying directly on a columnar border $(n=3)$ had no clear preference for one or the other column, their dendritic fields extended nearly equally into both columns. These cells were not included in the analysis. The shape of the basal dendritic arbors of pyramidal cells was also not influenced by columnar borders.

\section{Dendritic fields at columnar borders: strabismic animals}

In strabismic animals, Dil-labeled ocular dominance columns usually appeared to be sharper and more precisely demarcated from each other than in normal animals. Similar observations had been made after labeling ocular dominance columns in strabismic animals with ${ }^{3} \mathrm{H}$-proline injections into one eye (Shatz et al., 1977; Löwel, 1994). Spiny stellate cells near these sharp borders between the ocular dominance columns had pronounced asymmetric dendritic fields (Fig. 8). The dendritic fields of 57 spiny stellate cells was analyzed quantitatively. In most cells, the dendritic half-field facing toward the border usually was less dense, had fewer dendrites, and sparse dendritic branching compared to the half-field facing away from the border. In the immediate vicinity of the border (cell hody distance $<40 \mu \mathrm{m}$ ), almost all cells ( $91 \%, n=14$ ) were clearly biased, with significantly more dendritic intersections in the half-field facing away from the border than toward it ( $p<0.005$; Wilcoxon rank test). Cells laying further away $(>40 \mu \mathrm{m})$, were not influenced by the presence of the columnar border and they had nearly symmetrical dendritic fields (Fig. 9). Spiny stellate cells of strabismic animals not only showed a strong asymmetry in their dendritic fields, the analysis of the mirror index also revealed that their dendrites respected the columnar border more closely than in normal animals $(p<0.0005$; Wilcoxon rank test; Fig. 10).

\section{Dendritic fields at columnar borders: monocularly deprived animals}

In monocularly deprived animals, the dendritic bias of spiny stellate neurons near the borders of ocular dominance columns 
A

original position
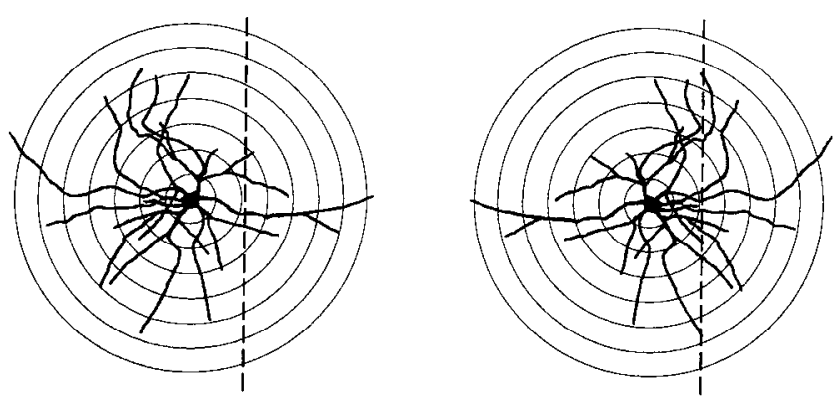

B

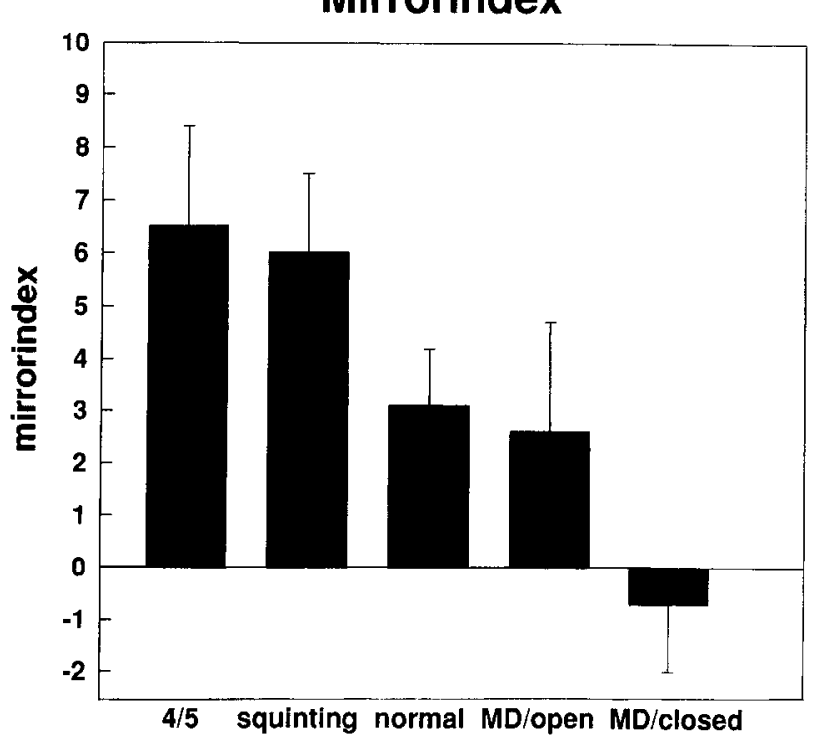

Figure 10. Mirror-index analysis of the dendritic fields of spiny stellate cells at the laminar and columnar borders of the thalamic afferents (distance $<80 \mu \mathrm{m}$ ). $A$, spiny stellate cell near the border between two ocular dominance columns (dashed line). Cell before (left) and after (right) mirror-imaging at a line running through the cell body, parallel to the columnar border. More dendrites cross the border after mirrorimaging, indicating that the cell's dendrites avoid the adjacent ocular dominance column. See text for further details. $B$, average mirror-index of spiny stellate cells at the border between layer 4 and layer 5 in normal animals (4/5), and at the columnar borders in strabismic (squinting), normal (normal), and monocularly deprived cats (MD/open, MD/ closed).

was different for cells located in the columns of the deprived ( $n$ $=37)$ and nondeprived eye $(n=45)$. In the columns of the deprived eye there was only one cell whose dendrites appeared to avoid the adjacent column of the open eye. The dendritic fields of the remaining cells $(86 \%, n=7)$ near columnar borders (cell body distance $<40 \mu \mathrm{m}$ ) exhibited a negative bias index. Thus, these cells had more dendrites running toward than away from the border ( $p<0.06$, Wilcoxon rank test; Figs. 9, 11). This effect was significantly different from the behavior seen in normal and strabismic cats where the dendrites of spiny stellate cells avoided to cross into neighboring ocular dominance columns $\left(\chi^{2}\right.$ test, $\left.p<0.01\right)$.
The presence of a columnar border had only a weak influence on the dendritic fields of spiny stellate cells located in the nondeprived ocular dominance columns. The dendrites of some cells avoided the columns of the deprived eye (Fig. 11); other cells extended their dendrites freely across columnar borders. Unfortunately, we only recovered three spiny stellate cells within 40 $\mu \mathrm{m}$ from the columnar border; thus, we do not known whether the dendritic bias of these cells was quantitatively different from the dendritic bias observed in normal animals. For the total sample of cells there was a large scatter in the bias index (Fig. 9) as well as in the mirror index (Fig. 10). As a result, neither the bias nor the mirror index was statistically different from zero.

\section{Discussion}

In the present study, we examined the dendritic morphology of neurons in the recipient zone of geniculocortical afferents in area 17 of normally raised, monocularly deprived, and strabismic cats. Irrespective of the visual experience of the animals, spiny stellate cells near the upper and lower margin of this zone had highly asymmetric dendritic fields and thereby confined their dendrites to the thalamorecipient region. Pyramidal neurons did not exhibit such dendritic asymmetries. Analysis of spiny stellate cells with respect to borders between adjacent ocular dominance columns indicated that visual experience can alter the structure of the dendritic fields of these cells: dendritic asymmetries depended both on the level and on the patterning of afferent input. These results then show that afferent activity not only affects the structure of presynaptic axonal terminals, but also the morphology of postsynaptic dendritic fields.

\section{Dendritic asymmetries at laminar borders}

A prominent feature of cortical organization is the grouping of cells with characteristic morphological and physiological properties into layers. The segregation of cortical cells into layers is reflected in the patterns of extrinsic afferent projections and intrinsic cortical connections, suggesting that the distinct functional properties observed in the different layers might be attributed to layer specific connections (for reviews, see Gilbert, 1983; Bolz et al., 1989). For instance, almost all cells in layer 4 of cat area 17 have small, simple receptive fields, while most cells in layer 5 have complex receptive fields that are 2-3 times larger than those in layer 4 (Gilbert, 1977; Leventhal and Hirsch, 1978). Layers 4 and layer 5 are sharply demarcated by the afferent terminals arising from the A laminae of the LGN, and they differ also in their intrinsic cortical input. Pyramidal neurons in layer 6 send axon collaterals specifically to layer 4 and avoid the intervening layer 5 , while pyramidal neurons in layers $2 / 3$ make collateral connections with layer 5 and avoid layer 4 (Gilbert and Wiesel 1979; Martin and Whitteridge, 1984; Katz, 1991). This clear segregation of thalamic and cortical inputs between layer 4 and layer 5 could play an important role in generating the characteristic response properties in these layers, provided that the segregation is maintained at the postsynaptic cells. The present results indicate that the dendrites of spiny stellate cells are oriented away from layer 5 and thereby avoid the mixing of layer-specific inputs. In contrast, the dendrites of spiny stellate cells near the borders between layers 3 and 4 freely crossed this laminar boundary. However, since we visualized simultaneously the cells' dendrites and the thalamic afferents, we found that they rarely extended outside the terminal fields of geniculocortical axons that project into the lower portion of layer 3. Thus, spiny stellate cells appear to be a homogeneous group 


\section{MD/open column}
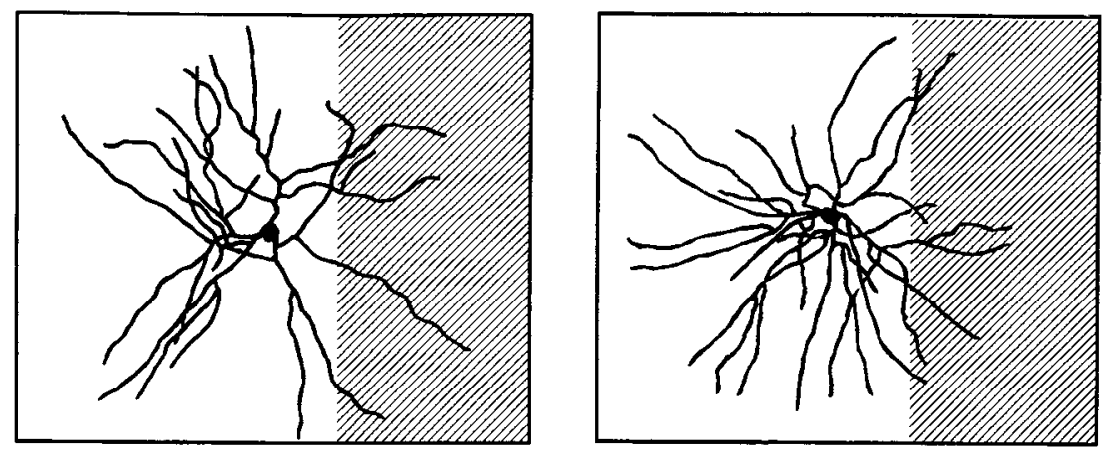

MD/ closed column
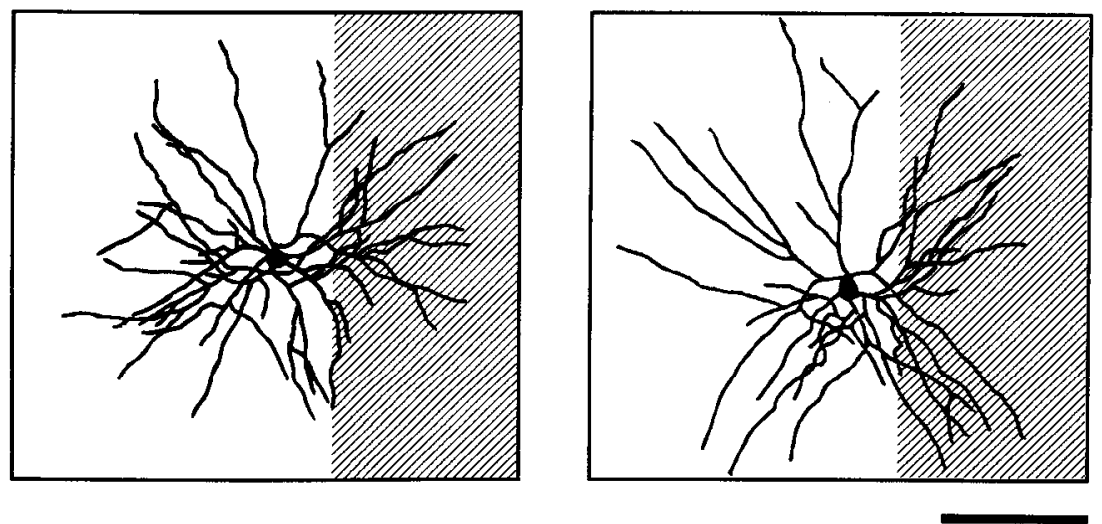

Figure 11. Spiny stellate cells near adjacent ocular dominance columns in monocularly deprived animals. The dendrites of cells laying in the columns of the open eye (MD/open column) tend not to cross into the neighboring column (the column of the deprived eye, hatched region). In contrast, cells laying in the columns of the closed eye (MD/closed column) not only freely crossed into the neighboring column, their dendrites were even biased toward the neighboring column, the column of the open eye. Scale bar, $100 \mu \mathrm{m}$. in having their dendrites confined to the main recipient zone of the thalamic afferents.

The shape of the dendritic fields of pyramidal neurons, unlike spiny stellate cells, was not affected by the thalamic afferents. The reasons for this striking difference are not known. In layer 4 of cat primary visual cortex, both spiny stellate cells and pyramidal neurons are a target for geniculocortical axons (Hornung and Garey, 1981; Stirling and Davis, 1979). Spiny stellate cells and pyramidal cells might differ in the portion of thalamocortical synapses or in other sources of innervation, but this has not yet been determined. It is also not known which cues spiny stellate cells, but not pyramidal cells, use to keep their dendrites within the recipient zone of thalamic afferents. Perhaps spiny stellate cells require the presence of thalamic fibers or a certain amount of synapses from these afferents in order to extend their dendrites. Another possible signal causing dendritic asymmetries might be differences in the activity between cortical layers. There is evidence for laminar differences in the amount of activity during early postnatal development. It has been shown that cells within layer 4 become responsive to visual stimuli during the first week after birth, about 2-3 weeks before cells in the neighboring layers 3 and 5 exhibit visual responsiveness (Albus and Wolf, 1984). Such different activity levels near laminar borders could influence the growth of the dendrites of spiny stellate cells. Finally, there might be intrinsic cortical cues independent of neuronal activity that regulate dendritic growth. Recent in vitro experiments provided evidence for molecular signals with- in the cortex that control the precise termination of thalamocortical fibers within their cortical target layer (Bolz et al., 1992; Götz et al., 1992; Yamamoto et al., 1992; for review, see Bolt et al., 1993). These positional cues located either on the surface of cells or within the extracellular matrix could either stimulate or inhibit the outgrowth of dendrites and thereby shape the dendritic trees of spiny stellate cells.

Whatever mechanisms underlie dendritic asymmetries at laminar borders, the differences in the organization of the dendritic fields between pyramidal and spiny stellate cells might have functional consequences. Simple cells are the predominant class in layer 4 , but there are also some cells with complex receptive fields that are often located near the border to layer 5 (Gilbert, 1977; Henry et al., 1979). The present results suggest that these cells might be pyramidal neurons whose dendrites cross the laminar border and thereby collect input from complex cells in layer 5. Intracellular recordings combined with dye injections revealed that all spiny stellate cells in layer 4 have simple receptive fields (Kelly and Van Essen, 1974; Gilbert and Wiesel, 1979, 1983; Lin et al., 1979; Martin and Whitteridge, 1984). Martin and Whitteridge (1984) also recovered a few pyramidal neurons with simple receptive fields, but all these cells were located near the center of layer 4 and had their dendrites confined to this layer. Thus, although there is no strict correlation of receptive field type to cell morphology throughout cortical layer 4 , such a correlation might exist near the borders of the thalamic afferents.

Dendritic asymmetries of spiny stellate cells near laminar bor- 
ders have also been observed in Golgi studies of primate striate cortex. In tree shrews and in macaque monkeys, spiny stellate cells show a striking horizontal stratification of their dendritic fields even within cortical layer 4 (Boothe et al., 1979; Lund, 1984). These dendritic asymmetries are related to subdivisions of layer 4 (layer $4 \mathrm{~A}$ in tree shrews and layers $4 \mathrm{C} \alpha$ and $4 \mathrm{C} \beta$ in macaques), which receive input from different thalamic axon populations. Thus, in primates, modifications of dendritic fields of spiny stellate cells not only occur at the borders between thalamic and nonthalamic inputs, but also hetween different types of thalamic input. In the cat, there are two major classes of geniculocortical afferents, called $\mathrm{X}$ - and $\mathrm{Y}$-cells (for review, see Sherman and Spear, 1982). Early anatomical tracing studies raised the possibility that $\mathrm{X}$ - and $\mathrm{Y}$-cells might have different sublaminar projection patterns within layer 4 of area 17 (Ferster and LeVay, 1978; Gilbert and Wiesel, 1979). However, more recent work indicated that the terminal fields of $\mathrm{X}$ - and $\mathrm{Y}$-axons overlap substantially in this layer (Martin and Whitteridge, 1984; Humphrey et al., 1985), and in the present study we found no stratification of the dendritic fields within the depth of layer 4 .

\section{Dendritic asymmetries at columnar borders}

The formation of ocular dominance columns from initially overlapping afferents from the left and right cyc has scrved as a model system for activity-dependent cortical development. Over the last 25 years, a large number of investigators demonstrated the importance of neuronal activity and sensory experience for the structural remodeling of geniculocortical afferents (for reviews, see Constantine-Paton et al., 1990; Shatz, 1990; Stryker, 1991). In particular, the temporal patterning of neuronal activity has been identified to convey the essential information for axons to segregate into eye-specific patches. Furthermore, a recent study demonstrated larger columnar spacings in strabismic compared to normal cats, indicating that the correlation of activity in thalamocortical afferents from the two eyes also influences the final expression of the columnar grid (Löwel, 1994). In contrast, very little is known about the consequences of the reorganization of the presynaptic terminals on the morphology of their postsynaptic target cells.

From carlicr work about the effects of sensory deprivation and lesioning on dendritic morphology of cortical neurons it was difficult to dissociate changes due to a loss of specific afferent activity patterns from alterations caused by a general loss of trophic support (for review, see Globus, 1975). Recent studies examining dendritic morphologies close to borders between adjacent ocular dominance columns allowed to distinguish between these possibilities. In both area Vl of macaque monkeys and in the tectum of three-eyed frogs, neurons close to these borders had their dendrites preferentially within the same eye-specific domain where their cell body was located (Katz and Constantine-Paton, 1988; Katz et al., 1989). This indicates that patterns of activity conveyed by afferent input, in addition to the presence or absence of afferent fibers themselves, can modulate the shape of dendritic arbors. These observations were confirmed and extended by the present results showing that various visual deprivation paradigms have specific effects on the structure of the dendritic fields of spiny stellate cells in cat area 17. Thus, different patterns of afferent activity causing different organizations of presynaptic terminals also influenced the dendritic morphology of postsynaptic neurons. In addition, a comparison of dendritic morphologies in normal and strabismic cats indicated that the degree of correlation of geniculocortical afferents from the left and right eye is also an important determinant for the structure of dendritic trees at columnar borders.

In normal cats, the dendrites of spiny stellate cells near the borders of adjacent ocular dominance columns remained preferentially within one column. This effect, however, was less pronounced than the one described for spiny stellate cells in macaque visual cortex (Katz et al., 1989). This might not be unexpected since the segregation of geniculocortical afferents in left and right eye patches in the cat appears to be less sharp than in the monkey (Shat7 et al., 1977; I eVay et al., 1980). Moreover, almost all cells in layer $4 \mathrm{C}$ in monkey striate cortex are monocular (Hubel and Wiesel, 1968), whereas only about $70 \%$ of the cells in layer 4 of cat striate cortex are strongly dominated by one eye or the other (Gilbert, 1977; Shatz and Stryker, 1978). The relatively high proportion of binocular cells in layer 4 in the cat could also be due to the presence of pyramidal cells which, as shown here, extend their dendrites freely across ocular dominance columns. Electrophysiological recordings combined with anterograde tracing indicated that binocular cells are intermingled with monocularly driven cells near columnar borders (Shatz and Stryker, 1978). This is consistent with our anatomical findings that the dendritic bias is cell-class specific. The fact that pyramidal neurons are absent in layer $4 \mathrm{C}$ in monkey striate cortcx might therefore be one reason why there are only very few binocular cells in this layer.

If the degree of temporal correlation in afferent activity plays a significant role in structuring the postsynaptic dendritic fields at columnar borders, then neurons in the visual cortex of strabismic cats should be more affected than in normal cats. The results of the present study show that this is the case: dendritic trees of spiny stellate cells in layer 4 of strabismic cats were more asymmetric than in normal animals, demonstrating that reduced correlation in the activity of the two eyes not only enhances ocular segregation at the level of presynaptic axonal arborizations (Shatz et al., 1977; Löwel, 1994), but also at the level of postsynaptic dendritic fields. The segregation of the geniculocortical afferents is therefore reflected in the shape of the dendritic fields of a population of postsynaptic target neurons.

Our observations in monocularly deprived cats indicate that the dendritic morphology at columnar borders is not only influenced by the relative timing, but also by the relative amount of activity conveyed by the afferents from the two eyes. The dendritic fields of spiny stellate cells located in the columns of the open eye were only weakly, or not at all, influenced by columnar borders. Cells in the nondeprived columns that extend their dendrites into the deprived columns receive only a weak synaptic input from the deprived eye. Reconstructions of individual geniculocortical axons revealed that the terminal arbors of the deprived eye are reduced in size, are less dense, and have smaller synaptic boutons than terminal arbors of the nondeprived eye (Friedlander et al., 1991; Antonini. and Stryker, 1993). These changes most likely reflect the anatomical correlate of a reduced synaptic efficacy. In addition, the segregation of left and right eye projections in monocularly deprived cats is less pronounced than in normal or strabismic cats (Shatz and Stryker, 1978). Therefore, dendrites extending into the column dominated by input from the deprived eye might still receive input from the nondeprived eye. Thus, compared to normal or strabismic animals, there are only weak constraints for cells in the column of the open eye to confine their dendrites to this column and to acquire asymmetric dendritic fields at columnar borders.

The situation is different for spiny stellate cells in the deprived 
columns. These cells receive input from the afferents serving the deprived eye, but due to their reduced efficacy, this synaptic input is relatively weak. Cells located near columnar borders also receive input from the nondeprived eye. The afferents from the open eye are highly active and therefore have a functional advantage over the less active afferents from the deprived eye. Our findings indicate that cells in the deprived columns extend their dendrites into the nondeprived columns, that is, into regions of higher neuronal activity. This suggests that cells at columnar borders are dominated by inputs from the nondeprived eye, even though their cell body is located within the columns of the deprived eye. As a consequence, in monocularly deprived animals the anatomical borders detined by anterograde labeling of the afferents do not coincide with functionally defined borders for eye preference. In fact, studies that have combined anterograde proline labeling with electrophysiological recordings within layer 4 indicate that cells often remain driven by the input from the nondeprived eye even though the electrode entered the columns of the deprived eye (Shatz and Stryker, 1978). The morphology of these cells has not been determined, but our results suggest that these cells might be spiny stellate cells.

In line with Hebb's postulate for associative learning (Hebb, 1949), physiological studies showed that synaptic contacts are strengthened when pre and postsynaptic activity is in synchrony, whereas synaptic contacts are weakened when this activity is asynchronous (Rauschecker and Singer, 1982; Bindman et al., 1988; Kossel et al., 1990; Frégnac et al., 1992; Shulz and Frégnac, 1992). It has been proposed that these changes in synaptic efficacy lead to a remodeling of the terminal arborizations of geniculocortical axons. Axon collaterals grow preferentially in cortical regions dominated by the same eye and are eliminated by the regions dominated by the other eye (LeVay et al., 1978; Antonini and Stryker, 1993). Our observation suggest that a similar remodelling also occurs at the level of the postsynaptic dendrites.

\section{References}

Albus K, Wolf W (1984) Early postnatal development of neuronal function in kitten's striate cortex; a laminar analysis. J Physiol (Lond) 348:153-185.

Antonini A, Stryker MP (1993) Rapid remodeling of axonal arbors in the visual cortex. Science 260:1819-1821.

Bindman LJ, Murphy KPSJ, Pockett S (1988) Postsynaptic control of the induction of long-term changes in efficacy of transmission at neocortical synapses in slices of rat brain. J Neurophysiol 60:1053-1065.

Bolz J, Gilbert CD, Wiesel TN (1989) Pharmacological analysis of cortical circuitry. Trends Neurosci 12:292-296.

Bolz J, Novak N, Staiger V (1992) Formation of specific afferent connections in organotypic slice cultures from rat visual cortex co-cultured with lateral geniculate nucleus. J Neurosci 12:3054-3070.

Bolz J, Gölz M, Hübener M, Novak N (1993) Reconstructing cortical connections in a dish. Trends Neurosci 16:310-316.

Boothe RG, Greenough WT, Lund JS, Wrege K (1979) A quantitative investigation of spine and dendrite development of neurons in visual cortex (area 17) of Macaca nemestrina monkeys. J Comp Neurol 186: $473-490$.

Constantine-Paton M, Cline HT, Debski E (1990) Patterned activity, synaptic convergence, and the NMDA receptor in developing visual pathways. Annu Rev Neurosci 13:129-154.

Ferster D, LeVay S (1978) The axonal arborizations of lateral geniculate neurons in the striate cortex of the cat. J Comp Neurol 182: 923-943.

Frégnac Y, Shulz D, Thorpe S, Bienenstock E (1992) Cellular analogs of visual cortical epigenesis. I. Plasticity of orientation selectivity. J Neurosci 12:1280-1300.

Friedlander MJ, Martin KAC, Wassenhove-McCarthy D (1991) Effects of monocular visual deprivation on geniculocortical innervation of area 18 in cat. J Neurosci 11:3268-3288.

Gilbert CD (1977) Laminar differences in receptive field properties in cat primary visual cortex. J Physiol (Lond) 268:391-42.1.

Gilbert CD (1983) Microcircuitry of the visual cortex. Annu Rev Neurosci $6: 217-247$.

Gilbert CD, Wiesel TN (1979) Morphology and intracortical projections of functionally characterised neurones in the cat visual cortex. Nature 280:120-125.

Gilbert CD, Wiesel TN (1983) Clustered intrinsic connections in cat visual cortex. J Neurosci 3:1116-1133.

Globus A (1975) Brain morphology as a function of presynaptic morphology and activity. In: Developmental neuropsychology of sensory deprivation (Rieser AH, ed), pp 9-91. New York: Academic.

Göt7. M. Novak N Rastmeyer M, Bolz J (1992) Membrane bound molecules in rat cerebral cortex regulate thalamic innervation. Development 116:507-519.

Hcbb DO (1949) The organization of behavior. New York: Wiley.

Henry GH, Harvey AR, Lund JS (1979) The afferent connections and laminar distribution of cells in the cat striate cortex. J Comp Neurol 187:725-144.

Hornung J-P, Garey LJ (1981) The thalamic projection to cat visual cortex: ultrastructure of neurons identified by Golgi impregnation or retrograde horseradish peroxidase transport. Neuroscience 6:10531068.

Hubel DH, Wiesel TN (1962) Receptive fields, binocular interaction and functional architecture in the cat's visual cortex. J Physiol (Lond) 160:106-154.

IIubel DII, Wiesel TN (1965) Binocular interaction in striale cortex of kittens reared with artificial squint. J Neurophysiol 28:1041-1059.

Hubel DH, Wiesel TN (1968) Receptive fields and functional architecture of monkey striate cortex. J Physiol (Lond) 195:215-243.

Hübener M, Bolz J (1992) Relationships between dendritic morphology and cytochrome oxidase compartments in monkey striate cortex. J Comp Neurol 324:67-80.

Humphrey AL, Sur M, Uhlrich DJ, Sherman SM (1985) Projection patterns of individual $\mathrm{X}$ - and $\mathrm{Y}$-cell axons from the lateral geniculate nucleus to cortical area 17 in the cat. J Comp Neurol 233:159-189.

Katz LC (1991) Specificity in the development of vertical connections in cat striate cortex. Eur J Neurusci 3:1-9.

Katz LC, Constantine-Paton M (1988) Relationships between segregated afferents and postsynaptic neurones in the optic tectum of three-eyed frogs. J Neurosci 8:3160-3180.

Katz LC, Gilbert CD, Wiesel TN (1989) Local circuits and ocular dominance columns in monkey striate cortex. J Neurosci 9:1389_ 1399.

Kelly JP, Van Essen DC (1974) Cell structure and function in the visual cortex of the cat. J Physiol (Lond) 328:515 547.

Kossel A, Bolz J (1992) Influence of thalamic projection patterns on dendritic morphologies of cells in layer 4 in cat visual cortex. Soc Neurusci Abstr 18:1305.

Kossel A, Bonhoeffer T, Bolz J (1990) Non-Hebbian synapses in rat visual cortex. Neuroreport 1:115-118.

LeVay S, Gilbert CD (1976) Laminar patterns of geniculocortical projection in the cat. Brain Res 113:1-19.

LeVay S, Stryker MP, Shatz CI (1978) Ocular dominance columns and their development in layer IV of the cat's visual cortex: a quantitative study. J Comp Neurol 179:223-244.

LeVay S, Wiesel TN, Hubel DH (1980) The devclopment of ocular dominance columns in normal and visually deprived monkeys. J Comp Neurol 191:1-51.

Leventhal AG, Hirsch HVB (1978) Receptive field properties of neurons in different laminae of visual cortex of the cat. J Neurophysiol 41:948-962.

Lin C-S, Friedlander MJ, Sherman SM (1979) Morphology of physiologically identified neurons in the visual cortex of the cat. Brain Res 172:344-348.

Lorente de Nó R (1938) Cerebral cortex: architecture, intracortical connections, motor projections. In: The physiology of the nervous system (Fulton JF, ed), pp 291-329. London: Oxford UP.

Löwel S (1994) Ocular dominance column development: strabismus changes the spacing of adjacent columns in cat visual cortex. J Neurosci $14: 745 I-7468$.

Löwel S, Singer W (1992) Selection of intrinsic horizontal connections 
in the visual cortex by correlated neuronal activity. Science 255:209212.

Lund JS (1984) Spiny stellate neurons. In: Cerebral cortex, Vol I (Jones EG, Peters A, eds), pp 255-308. New York: Plenum.

Martin KAC, Whitteridge D (1984) The relationship of receptive field properties to the dendritic shape of neurons in the cat striate cortex. J Physiol (Lond) 356:291-302.

Rauschecker JP, Singer W (1982) Binocular deprivation can erase the effects of preceding monocular or binocular vision in kitten cortex. Dev Brain Res 4:495-498.

Rosenquist AC, Edwards SB, Palmer LA (1974) An autoradiographic study of the projections of the dorsolateral geniculate nucleus and the posterior nucleus in the cat. Brain Res 80:71-93.

Shatz CJ (1990) Impulse activity and the patterning of connections during CNS development. Neuron 5:745-756.

Shatz CJ, Stryker MP (1978) Ocular dominance in layer IV of the cat's visual cortex and the effects of monocular deprivation. J Physiol (Lond) 281:267-283.

Shatz CJ, Lindström S, Wiesel TN (1977) The distribution of afferents representing the right and left eyes in the cat's visual cortex. Brain Res 131:103-116.
Sherman SM, Spear PD (1982) Organization of visual pathways in normal and visually deprived cats. Physiol Rev 62:738-855.

Sholl DA (1953) Dendritic organization in the neurons of the visual and motor cortices of the cat. J Anat 87:387-406.

Shulz D, Frégnac Y (1992) Cellular analogs of visual cortical epigenesis. II. Plasticity of binocular integration. J Neurosci 12:1301-1318.

Sterling P, Davis TL (1979) Microcircuitry of cat visual cortex: classification of neurons in layer IV of area 17, and identification of the patterns of lateral geniculate input. J Comp Neurol 188:599-628.

Stryker MP (1991) Activity-dependent reorganization of afferents in the developing mammalian visual system. In: Development of the visual system (Lam DMK, Shatz C, eds), pp 267-287. Cambridge, MA: MIT Press.

Wiesel TN, Hubel DH (1963) Single-cell responses in striate cortex of kittens deprived of vision in one eye. J Neurophysiol 26:1003-1017.

Wiesel TN, Hubel DH (1965) Comparison of the effects of unilateral and bilateral eye closure on cortical unit responses in kittens. J Neurophysiol 28:1029-1040.

Yamamoto N, Yamada K, Kurotani T, Toyama K (1992) Laminar specificity of extrinsic cortical connections studied in coculture preparations. Neuron 9:217-228. 